Article

\title{
Advocacy for Sustainability Communication: Unseen Potential of Queer Communicators in Environmental, Climate Change and Sustainability Science
}

\author{
Franzisca Weder* and Swastika Samanta
}

Citation: Weder, F.; Samanta, S.

Advocacy for Sustainability

Communication: Unseen Potential of

Queer Communicators in

Environmental, Climate Change and Sustainability Science. Sustainability 2021, 13, 13871. https://doi.org/ $10.3390 /$ su132413871

Academic Editor: Giovanni De Feo

Received: 4 November 2021

Accepted: 9 December 2021

Published: 15 December 2021

Publisher's Note: MDPI stays neutral with regard to jurisdictional claims in published maps and institutional affiliations.

Copyright: (c) 2021 by the authors. Licensee MDPI, Basel, Switzerland This article is an open access article distributed under the terms and conditions of the Creative Commons Attribution (CC BY) license (https:// creativecommons.org/licenses/by/ $4.0 /)$.
School of Communication and Arts, University of Queensland, St. Lucia, QLD 4072, Australia; s.samanta@uq.net.au

* Correspondence: f.weder@uq.edu.au

Abstract: The story of climate change, of destruction and loss, is well represented in mass media around natural hazards and new scientific data (i.e., the newest IPCC report); in contrast, new concepts of restoration, eco-cultural identities, social change and sustainable development are not picked up in public discourses-similarly to how the voices of NGO communicators, activists or queer communicators are not heard in the media. Additionally, the growth of digital publishing technologies and related audience behavior not only influence public communication processes, but also challenge professional communicators, including journalists and PR professionals to scientists, artists and activists. With a series of explorative interviews in different cultural settings (Central Europe, Australia, New Zealand), we can show that queer communicators have the potential to cultivate a new understanding of sustainability communication as social conversation about sustainability, and thus, overcome the very visible old story about climate change and rather propagate the new story of sustainability and transformation. The interviews show that queer communicator advocacy focuses on mobilizing and initiating dialectic conversations, which includes community building and queering existing norms, thus choosing new pathways for communication for sustainability. The findings and the developed concept of advocacy for sustainability communication are discussed at the end of the paper, including a reflection on the limitations of the explorative character of the analysis and future research potential.

Keywords: advocacy; queering; sustainability communication; science communication; agency; problematization

\section{Introduction}

While the old story of climate change, natural hazards, a global pandemic and environmental degradation is increasingly picked up by the media [1], which is further elaborated and discussed in the environmental and climate change communication literature [2-4]. There is a lack of public discourse about sustainability, sustainable development and social change in the media [5,6]. The reason for sustainability communication in the media being rather weak is that the complexity and inconvenience of sustainable development does not fit into the media logic. Neither abundance (less airflights, meat, travelling) and nor loss of welfare (less consumption) are easy to communicate; the long-term orientation of the transformation discourse does not fit into the short-term orientation of news media. Positive stories from green marketing and CSR communications are usually not picked up by mainstream media [5], because bad news is still good for news organizations.

Furthermore, a global development is not always easily broken down on a local or regional level; thus sustainability remains a blurry and complex term [7]), which is predominantly incorporated into the hegemonic, neoliberal discourse of the corporate world $[5,8]$. Thus, while news articles, editorial sections and supplements increasingly cover or are even dedicated to global warming and the changing climate, media communication on 
sustainability issues and sustainable development as an overarching process of change remain limited. How can this be overcome?

Today, science is present in public conversations. While COVID-19 has recently made health experts, scientists, doctors and virologists more visible the mediated public discourse, this has had an effect on the communication about global warming and the climate crisis. Here, experts and scientists are heard, while NGO-communicators, activists, and queer communicators in the area of environmental, climate change and sustainability communication are often pushed to the margins of public discourses by mainstream journalists and other, as mentioned above, professional (corporate) communicators [9].

Here, the unseen potential of science communicators to control not only of the old story about climate change, but also of the new story of sustainability and social change [10]; this unseen potential is to initiate and drive discourses around a changing climate and solutions for a sustainable development and transformation. Particularly by speaking to and learning from queer science and environmental communicators within a larger sample of internationally comparative interviews (in Central Europe, Australia, Asia), we learn that advocacy is the key to move communicators from the margins to the center of public discourses. Advocacy, specifically in environmental and climate change communications, includes processes of jamming and queering heteronormative worldviews and overcoming the binary between the old climate change story and the new story of sustainability.

Following critical theories and pedagogies (Ref. [11], advocacy can be conceptualized as networking, community building by problematizing, engaging the public in raising awareness about environmental problems, and developing solutions (where sustainability comes in), using creative means (like eco-art) to create cracks in underlying systems of power, and to promote unsettling moments of reflection and debate [12] (p. 397).

Reflecting the small sample and reactive nature of the interviews as the main limitations of the study, this paper complements existing research on queering science communication by incorporating a communicator perspective, it goes beyond existing concepts of advocacy journalism [13] and research on sustainability discourses in the media and beyond. It develops a concept for advocacy in sustainability communication, and thus contributes to the wider studies of culture and sustainability communications, in addition to public communication of science, technology, and innovative solutions in societal transformation.

\section{Theoretical Background}

The theoretical background for developing a concept of advocacy in and for sustainability communication will be developed from a science, environmental and climate change communication perspective, inspired and complemented by critical and queer studies.

\subsection{Communicator Research and Science Communication}

Theoretical frameworks offered to understand communication are often reduced to the process of transmission of messages from a sender to a-more or less specific-receiver or audience. However, from a critical perspective, communication is more: it is described as practice, as "doing," therefore communication includes or emphasizes public discourses and negotiations, sense- and meaning-making processes, conversations and, other transformative aspects [14].

Over the past decades, stimulated by digitalization and mediatization processes and related changes in the media ecology, new communicator roles have emerged, with different degrees of influence on public discourses. Next to new professional communicator roles, such as Influencer [15-17], Blogger (Johnston \& Rowney, 2020) and Social Media Manager (Stieglitz et al., 2018), authors theorize non-professional individuals communicating via social media channels, such as Idea Starters, Amplifiers, Commentators and Viewers [18]). Furthermore, communicators are more generally framed as curators [19], or individuals who use a broader context to define ideas; influencing the way conversations and discourses are shaped and spread, they validate topics, possibly challenge them and tailor information in a certain way [18]. Related to social media communicators and new communicator roles, 
such influencers, bloggers, activists and campaigners, other studies have created broader role concepts, such as customer service provider, mobilizer, information disseminator, researcher, and community builder [20].

This is where the study at hand started, introducing a new approach to communication as a reproductive and transformative process $[21,22]$ to better understand the changes in communicator roles defined by the drive to publish certain social and scientific ideas or to mirror relevant and burning issues back to society at large, or at least certain societal (sub)systems, which includes the construction of social reality and sense- and meaning making processes [23] (p. 184). Science communication in particular has been stimulated stimulated through new pathways of communication and digital media innovations [24]. As mentioned above: "A widening range of formats is being deployed in presenting science in public", in particular performance, musical and digital and visual arts [24] (p.4). Equally important for the study at hand is that science communication is increasingly seen as culture [25]. Instead of the functional, instrumental idea of communication of science, as mentioned above as the dominant perspective in the science of science communication, authors increasingly focus on the creation of meaning and (common) sense, and on the communicators who initiate, facilitate and drive these processes.

From this social-constructivist perspective, science communication includes how particular societies or groups, i.e., communicators who align with the LGBTQ+-community, explain the world [26] (p.3). Recently, Bucchi and Trench [24] asked: "how does society then talks about science, social change and transformation processes?" At this point, determining how climate change is presented and investigating how society talks about a changing environment and climate is a first step in answering this question.

\subsection{Climate Change \& Environmental Communication}

If science communication is conceptualized as the "social conversation around science" [24], then, from an environmental and sustainability communication perspective, the question should be re-formulated to: "what is the social conversation about the climate crisis, who drives and dominates these conversations, who are the silent voices, and why there isn't a real social conversation about sustainability?"

Social conversations and public discourses are currently dominated by global crises around climate change, biodiversity loss, migration, and a massive health crisis (COVID-19). At the same time, they are shaped by the advent of scientific and technological solutions to these problems (e.g., artificial intelligence, genetic modification, geo-engineering). As mentioned in the introduction, climate change is the underlying narrative of destruction and imbalance between humans and nature [10]. Although droughts, floods, and bushfires are omnipresent in the media, there is lack of public discourse about sustainability. However, an increasing number of corporate and political actors communicate about sustainabilityand relate their activities to this narrative [5,27-29]. Here, sustainability seems to be a remedy proposed for climate change-related problems, and it is framed a solution or treatment recommended as a response to resource scarcity, natural catastrophes, economic unfairness, or social inequality.

This binary between the old story of climate change and the new narrative of sustainability [30] is one of the biggest challenges for science communication in the 21st century, and thus for science communicators working in the area of climate change and environmental communication. When scientific institutions and NGOs disseminate their findings, their research-based knowledge on ecological destruction and a global crisis informs, creates awareness and increases science literacy; the new story about harmony, balance, wellbeing, technological innovations, geo-engineering, carbon capture, storage systems and new energy resources, is largely disseminated by corporate and political actors. There seems to be a lack of conversations or discourses that challenge this binary, and there is a lack of mobilizers and curators of these conversations, as defined above.

Here, the literature suggests NGOs act as alternative science communicators [31], if we understand alternative science communication, as communication that does not come 
from scientific institutes, or institutional science communication, as being more democratic. Furthermore, activists, campaigners and artists, mentioned as alternative science communicators [9,32] have that same role mirrored in environmental communication research [4] which points out that activists should not merely take the instrumental or pragmatic roles of transmitting or disseminating information, or of educating or persuading certain publics. Alternative science communicators define specific developments as problems that require societal and political attention, negotiation, decision making and change [9]. Moreover, feminist theory contributes to science communication by emphasizing the need to "learn from marginalized publics" [33] (p. 4), including a stronger focus on power relations, equity and diversity, and the inclusion of queer communities in research [34] We assume that queer science communicators can potentially bring in a new perspective on science communication and conversations about climate change and sustainable development, surpassing the ways and means that are used to communicate and overcoming the binary of the old and the new stories by challenging the binary itself. The advocacy that comes along with this is discussed below.

\subsection{Advocacy for Problematization}

Alternative communicators, as defined above, are not only conceptualized regarding the organization they work for or their professional role (NGO communicator, campaigner, activist). The role of an alternative communicator includes the concept of "the other" and therefore queer people or communities. Queer is $[35,36]$ the umbrella term for a wide variety of people across a spectrum of sexual orientations. Going beyond the role framework, we want to introduce the idea of queering as an "instructional, communicative and performative act which challenges heteronormativity" [33]. Queering highlights worldviews that run alongside public discourse, that sit in the margins [33], that overcome binaries ("old story" vs. "new story") and abused master narratives like sustainability.

If this is done purposefully, queering means problematization, a process of permanent contestation, stimulation of dissent, and the testing of hegemonic arguments [22]. This has been applied by Weder (ibid.) to Public Relations professionals and is conceptualized similarly by queer studies critics [33,37]. From a communication studies perspective, problematization is the creation of confusion over an issue, as understood in Weder's studies on retelling the story of sustainability [38]. Problematization is a key term in Foucault's work, in which problematization was a method of scrutinizing of truths taken for granted $[39,40]$. Here, problematization is conceptualized as a social practice of challenging existing perspectives or practices. We further assume that problematization is happening communicatively [38], as a process of (ethical) reflection, of critical thinking and dialogue and a demythicisation of common knowledge or common-sense issues [41,42].

Problematization allows actions to emerge from it. It invites the transformation of situations and increasing the level of involvement by communication [43]. Therefore, it can be assumed that people who experience changes, who are critical and conscious about injustice, disadvantages and marginalization are more likely to problematize, to crack in existing patterns of meaning in structures and existing binaries. Thus, as part of an explorative research project, we began conversations with queer communicators with backgrounds in environmental, climate and sustainability sciences, trying to answer the following questions: how do communicators describe their "role" and "doing communication", How much does "belonging to the queer community" influence their communications about science, environmental issues, climate change and sustainability, and how can we further define "advocacy" for sustainability communication?

\section{Methodology}

With a series of semi-structured qualitative interviews [44,45], conducted in a dialogue format with individuals, existing conceptual and ideological frameworks were targeted for complements and broadening [46] (p. 314). The interviews were set up as conversations with 
PR experts and campaigners, journalists, citizen journalists, influencers, bloggers, activists and artists in the area of environmental, climate change and sustainability communication.

The interviews aimed to critically evaluate changes in role perceptions of the communicators and the education backgrounds, skillsets, normative frameworks and ideologies needed for "doing sustainability communication". The interviews with queer communicators as a subset of conversations were conducted in NZ (2021, $n=9)$, Australia (2021, $n=15)$ and Germany $(2021, n=5)$. The analysis of the transcribed interview data was conducted with a specific form of qualitative text analysis [47], supported by QCAmap software [48,49], which enables a two-step process of category building, with a more specific coding of phrases and narrative elements followed by the building of general categories like problematized aspects, role description, and the norms, values and practices of communication.

\section{Results}

Overall, the interviews and conversations show that communicators who allied themselves with the queer community tend to advocate for sustainable development and communicate a rather positive constructive view of (and for) the future. The queer communicators we talked to worked predominantly as journalists, bloggers or activists, or at least mentioned that they take part in social movements like climate strikes. Most of the interviewees were prolific social media users and they identified themselves as creators or curators of social conversations about scientific facts, social change processes and related developments.

This supports the assumption that there is, firstly, a strong motivation in terms of climate change, environmental and sustainability communication to problematize, which is the core of advocacy communication, as conceptualized above. Secondly, conversational problematization was described by the interviewees as "stepping on other people's toes" (Interviewee \#5, in the following abbreviated as I\#5), "asking a lot of questions, even the uncomfortable ones" (I\#32) and finding new pathways to communicate facts and insights from climate change research with a stronger solution approach. While sustainability as a narrative of the future was mentioned only rarely, individual actions and behavior were seen as influential, and the communicators perceived their role as agency and advocacy for change.

\subsection{Advocacy as Mobilization}

As mentioned above, the explorative interviews enabled new insights in how science and, in particular, environmental and climate change communicators narrate themselves and how they perceive and address the binary between the old story of destruction and the new story of sustainability. The interviewees often mentioned that environmentalism seems to be stronger in the LGBTQ+ community than in the heterosexual population. Mainly blogger and influencer see "acting sustainable" and "being green" as naturally connected to being queer: "It is queer to recycle, to keep composting worms in the house, to spend hours a week in a kitchen garden, to try to eat ... no conventionally grown vegetables" (I\#2). The conversation about "being revolutionary" and therefore, being able to problematize the existing understanding of the world, which could be theoretically framed as "queer world-making" (Roberson \& Orthia, 2021), was even more insightful. One of the interviewed journalists mentioned that the process of coming out and claiming your identity is revolutionary per se; this means that nearly everything that is said has the character of mobilizing, which leads to communication being mostly "mobilizing the community for social and environmental action" (I\#5).

The interviews show that, while the character of mobilization needs courage (I\#2), it helps in working as a communicator, because it brings along responsibility for what is possible in the world around us. Therefore, one aspect of queer communication from an environmental and climate change perspective is that communicators seem to understand themselves as mobilizers. 


\subsection{Advocacy as Community Building}

The narrative interviews included the question of how particular groups (queer community) explain the world (Davies et al., 2019); thus, it was a nice fit to see one interviewee pointing out that community is what gives stability (I\#4), in the sense communities and (professional) networks are needed, because they help to create, pitch, and disseminate stories. This supports the research indicating that queer individuals work for/in "queerflavored science communication products" (Youtube, Podcasts etc.) [33]. One of the science communicators on Youtube indeed stated that "our environment is sustained through collective effort and mutual respect", which leads to solidarity, stability, resilience (I\#7), and a common agenda. "I do have an agenda, oh yeah", said one of the podcasters (I\#15); leading us to identify more aspects of advocacy in the interviews.

Similar to the podcaster, one filmmaker said: "I obviously believe in climate change and things are just going to continue to worsen ... people are going to be disproportionately impacted" (I\#2). We need to "create an ecologically sustainable (even regenerative) society" stated another environmental journalist, who continued by discussing activism: "We need to act, not to react"; "Queer allyship is active. As queer and trans climate justice advocates, our fight is deeply personal" (I\#3, emphasis in original). Moreover, the interviewees pointed to the importance of creating conversational spaces, which represents again the innovative idea of science communication as a social conversation around science [24]. Another communicator stated that "queer people are activists", and that they bring their whole selves to their professional role, which makes organizations a more inclusive space (I\#8). Advocacy emerges from community building and networking, as described above; this is related to identity building, and alignment with a group of people with "more courage-and less old, white men" (academic interviewee, business communicator, I\#7/2), a perspective supported by a social media manager who said that queer people use "peer groups ... friends to reclaim their identity" (I\#18).

These findings point to the connection between climate science communication, social change processes, sustainable development and transformation [50].

\subsection{Advocacy for Sustainability}

The findings have shown so far that mobilizing means to "make an issue out of something" (I\#8), of which nobody else would make an issue. Social conversations around science, as conceptualized above with respect to [24] embraces all that is being said on a certain matter in society; the method of advocacy communication we bring in with the findings at hand is thus more inclusive. One of the interviewees (academic and science journalist; I\#9) said that "It's not an either or, you know, ecology or social justice; they are intimately tied together." Conversations emphasize long-term continuity in science communication. Queer communicators therefore open (mobilize, initiate, stimulate) more complex learnings beyond hegemonic norms. "Queer identity needs not to be grounded in any positive truth or in any stable reality [but instead] acquires its meaning from its oppositional relation to the norm" [51] (p. 62).

So, we see queer advocacy for communication on sustainable development as something that goes beyond information and transmission processes, and even beyond individual values. Instead, it includes the initiation, facilitation, and maintenance of conversations around certain issues. Here, queer communicators play a significant role, mainly in initiating conversations. This means that queering, as a process sits at the beginning of "social conversations around science" [24]. As outlined in the literature section of this paper, queering is a process generating a "disturbance" of one or several dominant norms or common-sense beliefs, which is sometimes described as troubling, or finding the key for stimulating or entering a conversation with a specific contribution to the issue at hand. On this point, the interviewees supported the theoretical conceptualized relevance of problematization and the cracking or jamming of norms, as described in the literature. Queering, then, is "ethical artistry" [51] (p. 71), a transformative elaboration of resistance 
to dominant social norms. Refusing or problematizing the norm or the modes of life that are offered as common sense, offers a multiplicity of different pathways.

In a sustainability context queering is to advocate for a certain story about the future, develop a solution in relation to the extant problems of an environmental or social crisis, to create possibly revolutionary endings to this story (sustainability communication), and to embark on a new, more sustainable conversation, which includes problematization and the capability to "change our own constructions of the world and thereby to create new possibilities for our own action" [52] (p. 22). Advocacy for sustainability communication means evolving agency and consciousness and taking an active role in shaping the conversation about scientific facts regarding the changing climate, inclusive of the revolutionary ending just mentioned, thus developing more reflective awareness and pro-environmental behavior $[10,53]$.

\section{Discussion and Outlook}

In this paper, sustainability communication was defined as an activist discipline that has the potential to help shape restorative futures and practices. The interview data demonstrate that queering the binary between the old climate change story and a new revolutionary story of a sustainable future is a performative and communicative process. In the series of conversations with communicators in the area of sustainability, science, environmental and climate change communication, we identified rebels, queer and revolutionary science communicators and specific advocacy communicators. Examining this new, alternative type of communicators, this paper contributes to the existing understanding of queerness from a sustainability communication perspective. From a conceptual perspective, a new "queer identity" [51] is introduced: a communicator role that is bound in taking responsibility and advocating for a revolutionary ending to a crisis, an interventionist and mobilizer who uses communication not only to critique the status quo worldview and one having the potential to generate true transformation through conversational problematization $[12,22]$ (p. 395).

Secondly, the paper brings in a critical perspective on the role of communicators in initiating and facilitation conversations and creating a culture of sustainability. Thus, it stimulates more research on emerging new roles and communication as performance and as social practice in the context of climate change, sustainability and social change. The views of queer communicators with science backgrounds, however, need further research. This could further contribute to studies of cultural evolution, which is the study of how cultural traits (e.g., common sense, beliefs, norms and behavioral patterns) stabilize, change and diffuse in populations, and why some cultural traits, including sustainability, are more attractive (i.e., more likely to spread) than others. As such, more research on queering through communication would be highly relevant to the emerging field of sustainability communication [5] in that it can help organize and guide the study of sustainability communication efforts aimed at spreading scientifically accurate information and inspiring behavioral change [54].

Author Contributions: Conceptualization, methodology and interpretation, F.W.; formal analysis and investigation, S.S. All authors have read and agreed to the published version of the manuscript.

Funding: This research received no external funding.

Institutional Review Board Statement: The study was conducted according to the guidelines of UQ Research Ethics, approved by the board, \#2020002703, 17.12.2020.

Informed Consent Statement: Informed consent was obtained from all subjects involved in the study.

Data Availability Statement: The data is available via personal contact.

Conflicts of Interest: The authors declare no conflict of interest. 


\section{References}

1. Harcup, T.; O'Neill, D. What is news? News values revisited (again). J. Stud. 2017, 18, 1470-1488.

2. Schäfer, M.S.; Painter, J. Climate journalism in a changing media ecosystem: Assessing the production of climate change-related news around the world. Wiley Interdiscip. Rev. Clim. Chang. 2021, 12, e675. [CrossRef]

3. Pearce, W.; Niederer, S.; Özkula, S.M.; Sánchez Querubín, N. The social media life of climate change: Platforms, publics, and future imaginaries. Wiley Interdiscip. Rev. Clim. Chang. 2019, 10, e569. [CrossRef]

4. Cox, R. Environmental Communication and the Public Sphere; SAGE Publications Ltd.: London, UK, 2013.

5. Weder, F.; Krainer, L.; Karmasin, M. (Eds.) The Sustainability Communication Reader: A Reflective Compendium; Springer Nature: Berlin, Germany, 2021.

6. Barkemeyer, R.; Figge, F.; Holt, D.; Hahn, T. What the papers say: Trends in sustainability: A comparative analysis of 115 leading national newspapers worldwide. J. Corp. Citizsh. 2009, 69-86. Available online: https://www.jstor.org/stable/10.2307/jcorpciti. 33.69 (accessed on 18 September 2021).

7. Herrick, C.N.; Pratt, J.L. Communication and the narrative basis of sustainability: Observations from the municipal water sector. Sustainability 2013, 5, 4428-4443. [CrossRef]

8. Laclau, E.; Mouffe, C. Hegemony and Socialist Strategy: Towards a Radical Democratic Politics; Verso Trade: London, UK, 2014.

9. Fähnrich, B.; Riedlinger, M.; Weitkamp, E. Activists as "alternative" science communicators-Exploring the facets of science communication in societal contexts. JCOM 2020, 19, C01. [CrossRef]

10. Hendersson, H.; Wamsler, C. New stories for a more conscious, sustainable society: Claiming authorship of the climate story. Clim. Chang. 2020, 158, 345-359. [CrossRef]

11. Paiz, J.M. Queering practice: LGBTQ+ diversity and inclusion in English language teaching. J. Lang. Identity Educ. 2019, 18, 266-275.

12. Milstein, T.; Pulos, A. Culture Jam Pedagogy and Practice: Relocating Culture by Staying on One's Toes. Commun. Cult. Critique 2015, 8, 395-413. [CrossRef]

13. Vine, P. When is a journalist not a journalist?: Negotiating a new form of advocacy journalism within the environmental movement. Pac. J. Rev. 2017, 23, 43-54. [CrossRef]

14. Dewey, J. Democracy and Education; Macmillan Publishing: London, UK, 1916.

15. Enke, N.; Borchers, N.S. Social media influencers in strategic communication: A conceptual framework for strategic social media influencer communication. Int. J. Strateg. Commun. 2019, 13, 261-277. [CrossRef]

16. Johnston, J.; Rowney, K. Media Strategies: Managing Content, Platforms and Relationships; Routledge: London, UK, 2020.

17. Stieglitz, S.; Bunker, D.; Mirbabaie, M.; Ehnis, C. Sense-making in social media during extreme events. J. Contingencies Crisis Manag. 2018, 26, 4-15. [CrossRef]

18. Tinati, R.; Carr, L.; Hall, W.; Bentwood, J. Identifying Communicator Roles in Twitter, Proceedings of the 21st International Conference on World Wide Web (WWW '12 Companion), Lyon, France, 16-20 April 2012; Association for Computing Machinery: New York, NY, USA, 2012; pp. 1161-1168. [CrossRef]

19. Kramp, L.; Loosen, W. The transformation of journalism: From changing newsroom cultures to a new communicative orientation? In Communicative Figurations; Palgrave Macmillan: Cham, Switzerland, 2018; pp. 205-239.

20. Carpenter, S.; Lertpratchya, A.P. Social Media Communicator Roles: A Scale. Soc. Media Soc. 2016, 2, 2056305116632778. [CrossRef]

21. Falkheimer, J. Anthony Giddens and Public Relations: A third way perspective. Public Relat. Rev. 2007, 33, 287-293. [CrossRef]

22. Weder, F.; Milstein, T. (2020/Forthcoming) Revolutionaries needed! Environmental communication as an activist discipline and the potential of ecoculture jams in pedagogy and practice. In International Trends in Environmental Communication; Takahashi, B., Metag, J., Thaker, J., Evans Comfort, S., Eds.; Routledge: London, UK, 2020.

23. Dorer, J. The gendered relationship between journalism and public relations in Austria and Germany. A feminist approach. Communications 2005, 30, 183-200. [CrossRef]

24. Bucchi, M.; Trench, B. Introduction: Science Communication as the Social Conversation Around Science. In Routledge Handbook of Public Communication of Science and Technology; Routledge: London, UK, 2021; pp. 1-13. [CrossRef]

25. Horst, M.; Davies, S.R. Science communication as culture: A framework for analysis. In Routledge Handbook of Public Communication of Science and Technology; Routledge: London, UK, 2021; pp. 182-197. Available online: https://ebrary.net/162180/sociology / science_communication_culture_framework_analysis (accessed on 5 October 2021).

26. Davies, S.R.; Halpern, M.; Horst, M.; Kirby, D.S.; Lewenstein, B. Science Stories as Culture: Experience, Identity, Narrative and Emotion in Public Communication of Science. 2019. Available online: https://jcom.sissa.it/archive/18/05/JCOM_1805_2019_A0 1 (accessed on 5 October 2021).

27. Rasche, A.; Morsing, M.; Moon, J. Corporate Social Responsibility: Strategy, Communication, Governance; Cambridge University Press: Cambridge, UK, 2017.

28. Newig, J.; Schulz, D.; Fischer, D.; Hetze, K.; Laws, N.; Lüdecke, G.; Rieckmann, M. Communication regarding sustainability: Conceptual perspectives and exploration of societal subsystems. Sustainability 2013, 5, 2976-2990. [CrossRef]

29. Newig, J. Climate change as an element of sustainability communication. In Sustainability Communication: Interdisciplinary Perspectives and Theoretical Foundations; Godemann, J., Michelsen, G., Eds.; Springer: Dordrecht, The Netherlands, 2011.

30. Baker, T.; Weder, F. The Evolution of the Sustainability Story, Proceedings of the International Association for Media and Communication Research-IAMCR, Nairobi, Kenya, 11-15 July 2021; United States International University: Nairobi, Kenya. 
31. Maeseele, P. NGOs and GMOs: A case study in alternative science communication. Javn. Public 2009, 16, 55-72. [CrossRef]

32. Windfeldt, L. Activists as alternative science communicators. The NGO "Danish Seed Savers": Science communicators and activists but questionably alternative. J. Sci. Commun. 2020, 19, C05. [CrossRef]

33. Roberson, T.; Orthia, L.A. Queer world-making: A need for integrated intersectionality in science communication. J. Sci. Commun. 2021, 20, C05. [CrossRef]

34. Carpentier, N. Differentiating Between Access, Interaction and Participation. Conjunctions. Transdiscipl. J. Cult. Particip. 2015, 2, 7. [CrossRef]

35. Otis, H.N.; Dunn, T.R. Queer Worldmaking. In Oxford Research Encyclopedia of Communication. 2021. Available online: https: / / oxfordre.com/communication/view/10.1093/acrefore/9780190228613.001.0001/acrefore-9780190228613-e-1235 (accessed on 5 October 2021).

36. Duggan, L. Making it perfectly queer. In Theorizing Feminism; Routledge: London, UK, 2018; pp. $215-231$.

37. Mattheis, A.; De Arellano, D.C.R.; Yoder, J.B. A Model of Queer STEM Identity in the Workplace. J. Homosex. 2020, 67, 1839-1863. [CrossRef]

38. Weder, F.; Lemke, S.; Tungarat, A. (Re)storying sustainability: The use of story cubes in narrative inquiries to understand individual perceptions of sustainability. Sustainability 2019, 11, 5264. [CrossRef]

39. Foucault, M. The Concern for Truth. In Politics, Philosophy, Culture: Interviews and Other Writings, 1977-1984; Kritzman, L.D., Ed.; Routledge: New York, NY, USA, 1988; pp. 255-267.

40. Foucault, M. The Care of the Self. The History of Sexuality; Random House: New York, NY, USA, 1986; Volume 3.

41. Callon, M.; Latour, B. Unscrewing the Big Leviathan: How actors macrostructure reality and how sociologists help them to do so. In Advances in Social Theory and Methodology: Towards an Integration of Micro- and Macro-Sociologies; Knorr-Cetina, K., Cicourel, A.V., Eds.; Routledge: London, UK, 1981; pp. 277-303.

42. Weder, F. CSR as Common Sense Issue. In Handbook of Integrated CSR Communication; Diehl, S., Karmasin, M., Mueller, B., Terlutter, R., Weder, F., Eds.; Springer: Berlin, Germany, 2017; pp. 23-36.

43. Crable, R.E.; Vibbert, S.L. Managing Issues and Influencing Public Policy. Public Relat. Rev. 1985, 11, 3-15. [CrossRef]

44. Savin-Baden, M.; Major, C. Qualitative Research: The Essential Guide to Theory and Practice; Routledge: London, UK, 2013.

45. Lindlof, T.R.; Taylor, B.C. Qulitative Communication Research Methods, 2nd ed.; Sage: Thousand Oaks, CA, USA, 2002.

46. DiCicco-Bloom, B.; Crabtree, B.F. The qualitative research interview. Med. Educ. 2006, 40, 314-321. [CrossRef] [PubMed]

47. Rubin, H.; Rubin, I. Listening, hearing and sharing social experiences. In Qualitative Interviewing: The Art of Hearing Data; Sage: Thousand Oaks, CA, USA, 2005; pp. 1-18.

48. Mayring, P. Qualitative content analysis. Companion Qual. Res. 2004, 1, 159-176.

49. Mayring, P. Qualitative Content Analysis: Theoretical Foundation, Basic Procedures and Software Solution. Available online: https:/ / nbn-resolving.org/urn:nbn:de:0168-ssoar-395173 (accessed on 5 October 2021).

50. Fischhoff, B.; Scheufele, D.A. The sciences of science communication. Proc. Natl. Acad. Sci. USA 2013, 110, 14033-14039. [CrossRef] [PubMed]

51. Halperin, D. Saint Foucault: Towards a Gay Hagiography; Oxford University Press: Oxford, UK, 1995.

52. Burr, V. Social Constructionism, 3rd ed.; Routledge: London, UK; New York, NY, USA, 2015.

53. Brown, B. Rising Strong; Random House: New York, NY, USA, 2015; ISBN 9780091955038.

54. Theiss, B. How cultural evolution can inform the science of science communication-and vice versa. Humanit. Soc. Sci. Commun. 2020, 7, 135. 